\title{
Intestinal hydatidosis in unusual location: A case report
}

\author{
Nagarekha Kulkarni
}

\begin{abstract}
Introduction: Hydatid cyst in the small intestine is extremely rare and only a few cases have been reported in literature. Case Report: A 60-yearold male presented with abdominal pain in the periumbilical region, nausea and fever. Hematological investigations revealed neutrophilic leukocytosis with eosinophilia. Ultrasound scan revealed multiple hypoechoic cysts in the small intestine. Serological tests were positive for hydatid disease. Surgical laparotomy was done and patient was treated with antihelminthic drugs. Histological diagnosis of hydatidosis was made. Conclusion: Intestinal hydatidosis is a rare entity and can be considered as one of the differential diagnosis of acute abdomen or abdominal mass.
\end{abstract}

\section{Keywords: Hydatid cyst, Echinococcus, Hydatidosis}

Kulkarni N. Intestinal hydatidosis in unusual location: A case report. International Journal of Case Reports and Images 2013;4(2):103-107.

$* * * * * * * * *$

Nagarekha Kulkarni

Affiliations: ${ }^{1}$ Associate Professor, Department of Pathology, Vijayanagara Institute of Medical Sciences, Bellary, Karnataka, India.

Corresponding Author: Dr. Nagarekha Kulkarni, Associate Professor, Department of Pathology, Vijayanagara Institute of Medical Sciences, Bellary-583104, Karnataka, India; Ph: 08392 - 257700; Mob: +919449463366; Email: nagarekhaphaniraj1970@gmail.com

Received: 11 June 2011

Accepted: 24 October 2012

Published: 01 February 2013
doi:10.5348/ijcri-2013-02-271-CR-5

\section{INTRODUCTION}

Hydatid disease (Echinococcosis) is a parasitic disease caused by larval stage of Echinococcus granulosus, in which humans are accidental intermediate host and animals are both definitive and intermediate host [1]. It is endemic in the cattle grazing areas particularly Australia, New Zealand, Middle East, India, Africa, South America and Turkey. Humans get infected by consuming raw vegetables, undercooked animal products and water contaminated with the hydatid ova. Humans can also become infested after close contact with animals such as cats and dogs [2]. This disease is a major cause of morbidity and mortality in many parts of the world. In humans, liver is the most frequently affected organ followed by the lungs. The traumatic or spontaneous rupture of a hydatid cyst may put the patient's life at risk due to anaphylaxis by cyst contents. If the patient survives, the development of new hydatid cysts may lead to a difficult to treat situation [3]. Reports on cases of hydatid cysts involving the intestine are exceedingly rare. In Lyon's report of a series of 241 cases in North America the intestine was involved in only one case. There have been several cases reported as abdominal hydatids, but there was no mention of the intestinal involvement [4].

\section{CASE REPORT}

A 60-year-old male living in a rural area presented to surgical out patient department with abdominal pain, nausea and fever since 15 days. The abdominal pain was localized in the periumbilical region. The pain was intermittent and colicky with intense pain of 10-15 minutes followed by $2-3$ hours of remission. The pain aggravated after intake of heavy meals and during sleep. He had nausea $2-3$ hours after meals. The fever was 
mild and continous without any chills and rigors. Patient gave a history of similar dull, aching abdominal pain since one year. He had taken treatment from local practitioner who treated symptomatically and the diagnosis was not made. There were no past history of trauma, jaundice, alteration in bowel and bladder habits or surgery. The family history was unremarkable. Patient was nonalcoholic and nonsmoker. He had frequent contact with farm animals. The patients gave a past history of hypertension which was controlled by antihypertensive drugs. Physical examination revealed a mass in the periumbilical region measuring $8 \times 6 \mathrm{~cm}$. The mass was firm with restricted mobility. Clinically, a tumor in periumblical region was suspected. There was no hepatosplenomegaly. Bowel sounds were normal. The vital signs, laboratory results and radiographic findings of the patient are given in Table 1 . Hematological investigations showed leukocytosis with neutrophilia and eosinophilia. Serological tests indirect hemagglutination assay (IHA) and enzyme linked immunosorbant assay (ELISA) were positive for hydatidosis. Abdominal ultrasound scan revealed multiple hypoechoic cysts in the small intestine. Surgical laparotomy was done on the same day of admission. Intraoperative findings confirmed the diagnosis of intestinal hydatidosis. During surgery the exact location of the cyst was identified and the surrounding tissues were protected by covering them with cetrimide soaked pads. The cyst along with $15 \mathrm{~cm}$ of small intestine (jejunum) was removed and cetrimide was injected into the abdominal cavity. After 10 minutes cetrimide was evacuated and the abdominal cavity was irrigated with isotonic sodium chloride solution. Care was taken to ensure no spillage occurred to prevent seeding and secondary infestation. The abdominal cavity was then filled with isotonic sodium chloride solution and closed. Peroperatively liver and spleen were normal. There were no peritoneal deposits. Antibiotics were used prophylactically for surgery. Postoperative period was uneventful and the patient was discharged after 15 days.

Table 1: The patient's vital signs, laboratory and radiographic findings

\section{Vital Signs}

\section{Pulse Rate}

Blood Pressure (mmHg)

Respiratory Rate

Temperature $\left({ }^{\circ} \mathrm{C}\right)$

\section{Laboratory Findings}

Hemoglobin (g/dL)

RBC Count $\left(\times 10^{5} / \mathrm{mm}^{3}\right)$

Haematocrit

WBC count $\left(\times 10^{3} / \mathrm{mm}^{3}\right)$

Differential Count:

Neutrophils

Eosinophils

Lymphocytes

Total Bilirubin (mg/dL)

Alanine Transferase (IU/L)

Aspartate Transferase (IU/L)

Alkaline Phosphatase (IU/L )

Serological (Test): IHA

ELISA

\section{Radiographic Findings}

Chest X-ray

Abdominal X-ray
Normal

$$
\begin{aligned}
& \text { 92/minute } \\
& 130 / 80 \\
& 24 / \text { minute } \\
& 38.5
\end{aligned}
$$

10 (Normal: 13.6-17.2 g/dL)

3.2 (Normal: 4.5-5.5)

31\% (Normal: 35-50\%)

19x103 (Normal: 4-11)

90\%

o8\%

$02 \%$

0.9 (Normal: 0.1-1.2)

22 (Normal: up to 40)

34 (Normal: up to 40)

67 (Normal: 60-170)

Positive

Positive

Normal

Abbriviations: IHA - Indirect hemagglutination assay, ELISA - Enzyme linked immunosorbant essay 
Albendazole $400 \mathrm{mg}$ orally, twice daily was started after the surgery and continued for three months postoperatively. Postoperative follow-up was for one year. The complete blood counts and liver enzyme evaluation were performed at biweekly intervals for three months and then every four weeks to monitor for albendazole toxicity. Serology assay (ELISA and IHA) and ultrasonography was performed at 3rd, 6th, 12th month intervals as screening to monitor for recurrence of disease. No recurrence was noted after one year.

Fifteen centimeters of small intestine (jejunum) was sent for histopathological examination. Macroscopic

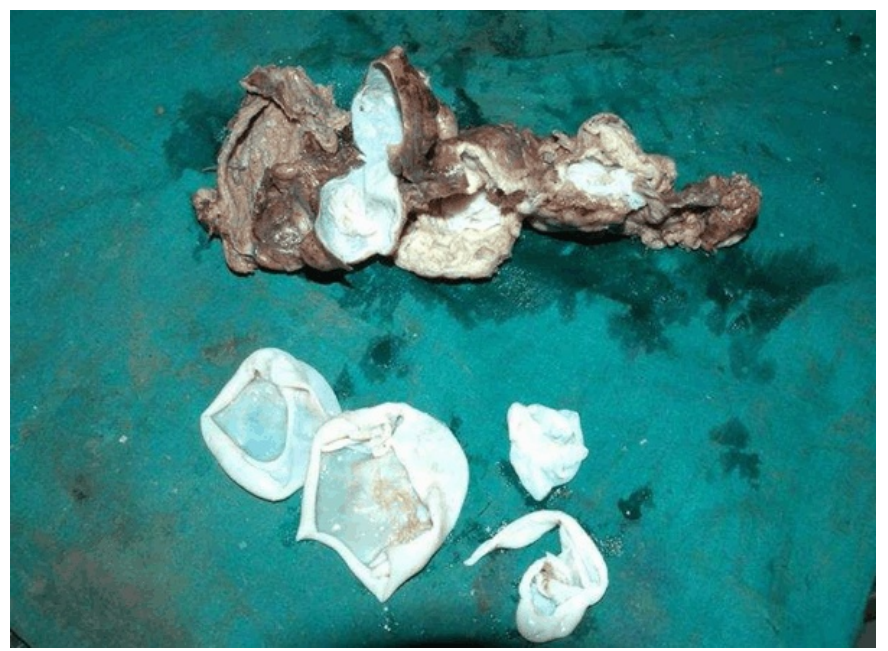

Figure 1: Gross appearance of hydatid cyst involving small intestine (jejunum).

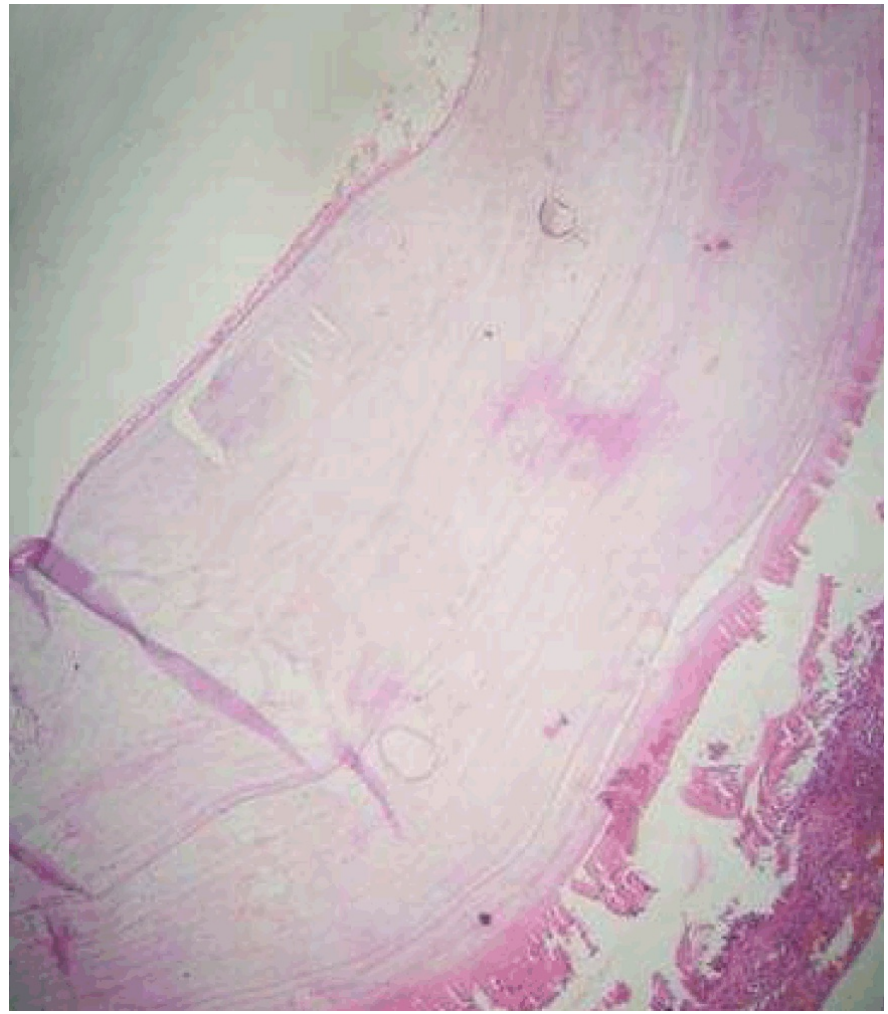

Figure 2: Histopathology of cyst showed features of hydatid cyst involving mucosa, submucosa and muscularis layer surrounded by chronic inflammatory cells (H\&E stain, 200x). examination of resected portion of jejunum showed multiple cysts in the wall of the intestine. The largest cyst was $8 \mathrm{~cm}$ in diameter. Cut section along the antimesentric border revealed multiple translucent cysts containing nonviscous fluid (Figure 1). Histological examination revealed features of hydatid cyst involving mucosa, submucosa and muscularis layer surrounded by chronic inflammatory infiltrate (Figure 2). The diagnosis of intestinal hydatidosis was made.

\section{DISCUSSION}

Hydatid disease is caused by Echinococcus granulosus, Echinococcus oligarthus and Echinococcus multilocularis. Echinococcus granulosus is most common and represents an important medical problem in many countries. Humans are accidental intermediate hosts infected by ingestion of food contaminated with eggs shed by dogs or foxes and are common in rural areas. Eggs hatch in the duodenum and enter the mesenteric venules and become lodged in the capillary filter bed in various organs except for hair, teeth or finger nails [5]. The most important site is liver (70\%), lung (15\%), kidney (3\%), spleen (4\%), cerebrum $(2 \%)$ and heart $(0.02-2 \%)$. The other sites that have been reported include bone, pancreas, breast, ovary, scrotum, thyroid gland, inguinal canal and soft tissue $[6,7]$. Hydatid cyst in the small intestine is extremely rare and only a few cases have been reported [8]. Majority of cases of hydatid disease come from rural areas or people who have settled in urban centers after spending life in villages. Most of the people acquire the disease during their childhood but they are asymptomatic until late adulthood because of the slow growing nature of the cysts [9].

Hydatidosis affects human beings without predilection for age or sex. In a study of 2,013 patients by the Tunisian Surgical Association, the mean age was 32 years [9]. Ayadi-Kaddour et al. reported a case in which the patient was 66 years old [5]. Clinical manifestations of hydatidosis in humans are variable. Most patient seem to tolerate the infection for extended periods with out any symptomatology or they may suddenly show dramatic and acute symptoms [10]. In a case reported by Najih et al., the patient presented with intermittent attacks of abdominal pain, abdominal distention, recurrent vomiting and nausea [11]. Kusaslan et. al. reported a case in which the abdomen was tense and tender, especially in the lower quadrant with guarding and rebound tenderness. Sometimes the clinical findings may mimic other abdominal disorders [9]. For an unusual location the diagnosis can be difficult; all abdominal cystic lesions including mesenteric, pancreatic, gastrointestinal duplication, ovarian cysts and lymphangioma must be considered in the differential diagnosis. Pain is the most common symptom of hydatid disease. Pain may be of acute onset if the cyst ruptures or it may be continous, dull, aching in nature. Fever may occur if there is secondary infection [12]. Although the physical findings are varied, 
the diagnosis is best made by a combination of hematological, biochemical and serologic laboratory investigations and by radiographic examination. Ultrasonography is the first line of screening test for abdominal hydatidosis. Computed tomography (CT) scan has become an extremely useful and valuable diagnostic tool in the management of patients with hydatidosis [7]. In the present study CT scan was not done as the diagnosis was made on ultrasound examination. The treatment of choice is surgical excision of the cyst alone or en bloc with a part or the whole involved organ with adjuvant therapy to prevent the recurrence. In this case the cyst was removed along with $15 \mathrm{~cm}$ of small intestine (jejunum) because of adhesions. Anaphylactic shock due to spontaneous or traumatic rupture or during surgery is a rare phenomena but with severe complications [13]. In the present case we did not come across anaphylactic reactions as cetrimide was injected into the abdominal cavity. Medical treatment with antihelmenthic drugs such as albendazole is used preoperatively and postoperatively. Some authors report better results when medical treatment is used along with surgical treatment [1]. Our patient was prescribed albendazole (400 mg orally, twice daily) after surgery and it was continued for three months postoperatively. Morbidity and mortality in patients with perforated hydatid cyst are higher than in those with nonperforated cysts. Mortality rate is variable, ranging from $0-20 \%$ in published reports of perforated cyst [5].

\section{CONCLUSION}

To conclude, intestinal hydatid cyst is a rare entity and can be considered as one of the differential diagnosis of acute abdomen or mass per abdomen. Serological, ultrasonography and CT should be performed before any invasive procedures. The complications of the disease can be potentially devastating. The disease still continous to challenge the public and health professionals with its rare presentations.

$$
* * * * * * * * *
$$

\section{Acknowledgements}

I thank Head of the department and all staff members of Department of Pathology, Surgery and Anaesthesia for their support and encouragement to prepare this report.

\section{Author Contributions}

Nagarekha Kulkarni - Substantial contributions to conception and design, Acquisition of data, Analysis and interpretation of data, Drafting the article, Revising it critically for important intellectual content, Final approval of the version to be published

\section{Guarantor}

The corresponding author is the guarantor of submission.

\section{Conflict of Interest}

Authors declare no conflict of interest.

\section{Copyright}

(C) Nagarekha Kulkarni et al. 2013; This article is distributed under the terms of Creative Commons Attribution 3.0 License which permits unrestricted use, distribution and reproduction in any means provided the original authors and original publisher are properly credited. (Please see www.ijcaserep

\section{REFERENCES}

1. Naila Nadeem, Hassan Khan, Saulat Fatimi, Mohammed Nadeem Ahmad. Giant multiple intra-abdominal hydatid cysts: a case report. J Ayub Med Coll Abbottabad 2006;18(4):71-3.

2. Polat P, Kantarci M, Alper F, Suma S, Koruyucu MB, Okur A. Hydatid disease from head to toe. Radiographics 2003;23(2):475-94.

3. Teke Z,Yagci AB,Atalay AO,Kabay B. Splenic hydatid cyst perforating into the colon manifesting as acute massive lower gastrointestinal bleeding: an unusual presentation of disseminated abdominal echinococcosis. Singapore Med J 2008;49(5):e113-6.

4. Lyon IP. A review of echinococcus disease in North America. Am J M Sc 1902;123-4.

5. Hadley MD. Occult hydatid disease presenting as a spontaneous pneumothorax. The British Journal of Radiology 1985;58(692):770-2.

6. Ayadi-Kaddour A, Mlika M, Yahyaoui M, El Mezni F. Intestinal hydatidosis: Uncommon location of hydatid cysts. Surgical Infections 2008;9(5):541-3.

7. Pedrosa I, Saiz A, Arrazola J, Ferreiros J, Pedrosa CS. Hydatid disease: radiologic and pathologic features and complications. Radiographics 2000;20(3):795-817.

8. Slocumb RH. Hydatid cyst of the appendix. JAMA 1927;89(15):1243.

9. Kusaslan R, Sahin DA, Belli AK, Dilek ON. Rupture of a mesenteric hydatid cyst: a rare cause of acute abdomen. Can J Surg 2007;50(5):E3-4.

10. Attef M Elshazly, Manar S Azab, Samar N Elbeshbishi, andHany M Elsheikha. Hepatic hydatid disease: four case report. Cases journal 2009;2(1):58.

11. Mohammed Najih, Ali Chabni, Gilles Attoulou, et al. Isolated primary hydatid cyst of small intestinal mesentery: an exceptional location of hydatid disease. Pan African medical Journal 2012;13:17.

12. Saidi F. Surgery of hydatid disease, ed 1. Philadelphia, Saunders 1976;112-21.

13. Col C, Col M, Lafci $\mathrm{H}$. Unusual localizations of hydatid disease. Acta Med Austriaca 2003;30(2):61-4. 
Access full text article on other devices

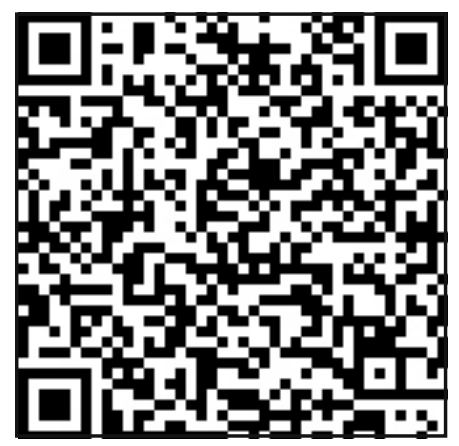

Access PDF of article on other devices

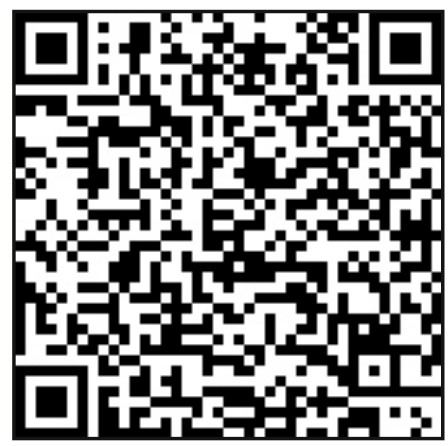

